TITLE:

\title{
Silicon dioxide thin films prepared by chemical vapor deposition from tetrakis(diethylamino)silane and ozone
}

\author{
$\operatorname{AUTHOR}(S)$ :
}

MARUYAMA, T; OHTANI, S

\section{CITATION:}

MARUYAMA, T ... [et al]. Silicon dioxide thin films prepared by chemical vapor deposition from tetrakis(diethylamino)silane and ozone. APPLIED PHYSICS LETTERS 1994, 64(21): 2800-2802

\section{ISSUE DATE:}

1994-05-23

URL:

http://hdl.handle.net/2433/43528

\section{RIGHT:}

Copyright 1994 American Institute of Physics. This article may be downloaded for personal use only. Any other use requires prior permission of the author and the American Institute of Physics. 


\title{
Silicon dioxide thin films prepared by chemical vapor deposition from tetrakis(diethylamino)silane and ozone
}

\author{
Toshiro Maruyama and Satoshi Ohtani \\ Department of Chemical Engineering, Faculty of Engineering, Kyoto University, Kyoto 606, Japan
}

(Received 3 February 1994; accepted for publication 23 March 1994)

\begin{abstract}
Silicon dioxide thin films were prepared by a low-temperature atmospheric-pressure chemical vapor deposition method. The raw materials were tetrakis(diethylamino)silane and ozone in oxygen gas. The amorphous films were obtained at a substrate temperature above $200^{\circ} \mathrm{C}$. The films were superior in chcmical stability and hardncss to the films which werc prepared from tetraethoxysilane and ozone.
\end{abstract}

Recently, the atmospheric-pressure chemical vapor deposition (CVD) method using tetraethoxysilane (TEOS) and ozone has attracted much attention because it gives better quality $\mathrm{SiO}_{2}$ films at low deposition temperatures $\left(350-400^{\circ} \mathrm{C}\right) .{ }^{1,2}$ In the meantime, the authors ${ }^{3}$ proposed tetrakis(dimethylamino)silane $\left\{\mathrm{Si}\left[\mathrm{N}\left(\mathrm{CH}_{3}\right)_{2}\right]{ }_{4}\right\}$ and ozone in oxygen gas as source materials. This system showed a characteristic low deposition temperature $\left(\geqslant 40^{\circ} \mathrm{C}\right)$, but the hardness of the deposited film is lower than that for TEOS-ozone system.

In this letter, tetrakis(diethylamino)silane $\left\{\mathrm{Si}\left[\mathrm{N}\left(\mathrm{C}_{2} \mathrm{H}_{5}\right)_{2}\right]_{4}\right\}$ and ozone in oxygen gas are proposed as source materials for obtaining $\mathrm{SiO}_{2}$ films by the atmosphericpressure CVD method. The deposition conditions, the structure, and hardness of the deposited film will be described in comparison with those for the CVDs from $\mathrm{Si}\left[\mathrm{N}\left(\mathrm{CH}_{3}\right)_{2}\right]_{4}$-ozone ${ }^{3}$ and TEOS-ozone system.

Figure 1 shows the schematics of the experimental apparatus and reactors. Tetrakis(diethylamino)silane (Shin-Etsu Chemical Co., Ltd.) was used as the silicon source. It is a liquid at room temperature. It was heated at a temperature of $60^{\circ} \mathrm{C}$, and the vapor was carried into the reactor with nitrogen gas as a carrier. The flow rate of the carrier gas was 300 $\mathrm{cm}^{3} / \mathrm{min}$. The ozone was generated in an ozonator which converts a fraction of the incoming oxygen gas. The flow rate of oxygen gas was $100 \mathrm{~cm}^{3} / \mathrm{min}$. A 6-W low-pressure mercury lamp (wavelength $184.9 \mathrm{~nm}$ ) was used as the ozonator. The ozone and oxygen gas were mixed with the vapor

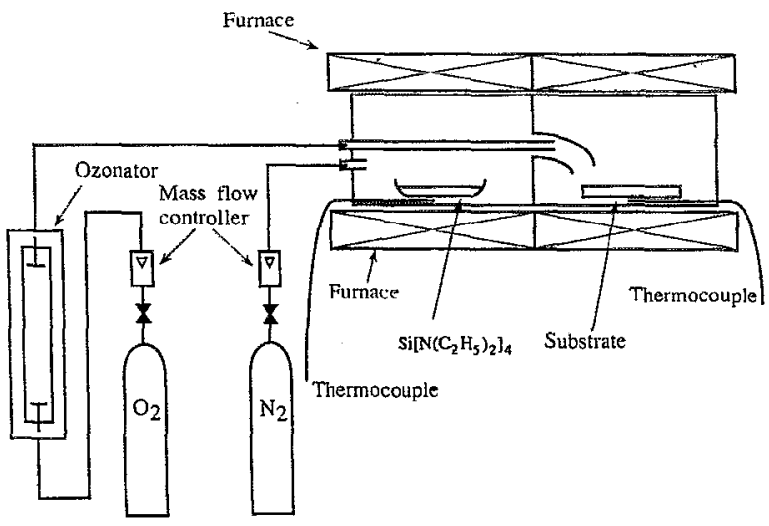

FIG. 1. Schematic representations of experimental equipment and reactors. of silicon source in the entrance nozzle. Silicon (100) singlecrystal wafers were used as substrates. In the reactor, the substrate was set horizontally. Depositions were made at atmospheric pressure. For comparison, the depositions from TEOS-ozone and $\mathrm{Si}\left[\mathrm{N}\left(\mathrm{CH}_{3}\right)_{2}\right\rceil_{4}$-ozone system were conducted in the same reactor under the same experimental conditions except the source temperature $\left(40^{\circ} \mathrm{C}\right)$.

The composition of the film was measured by $\mathrm{X}$-ray photoelectron spectroscopy. The infrared spectra were obtained by means of a Fourier transform infrared spectrometer (Shimadzu FTIR-4300). The samples were prepared by depositing films on silicon single-crystal substrates. The dynamic hardness of the film was measured with an ultramicrodynamic hardness meter (Shimadnu DUH-200). The etch rate was obtained by dipping the film into the P-etching solutions which consisted of $\mathrm{HF}, \mathrm{HNO}_{3}$, and $\mathrm{H}_{2} \mathrm{O}$ ( $\mathrm{HF}: \mathrm{HNO}_{3}: \mathrm{H}_{2} \mathrm{O}=3: 2: 69$ in weight). Ozone concentration was measured by means of a multipurpose recording spectrophotometer. "The absorbance at $253.7 \mathrm{~nm}$ showed that the ozone concentration for oxygen gas flow rate of $100 \mathrm{~cm}^{3} / \mathrm{min}$ was 463 ppm.

Transparent amorphous films were obtained at substrate temperatures above $200^{\circ} \mathrm{C}$. X-ray photoelectron spectroscopy showed that the films were near-stoichiometric $\mathrm{SiO}_{2}$ without containing nitrogen. The films showed smooth surface morphologies, and the particle generations were very

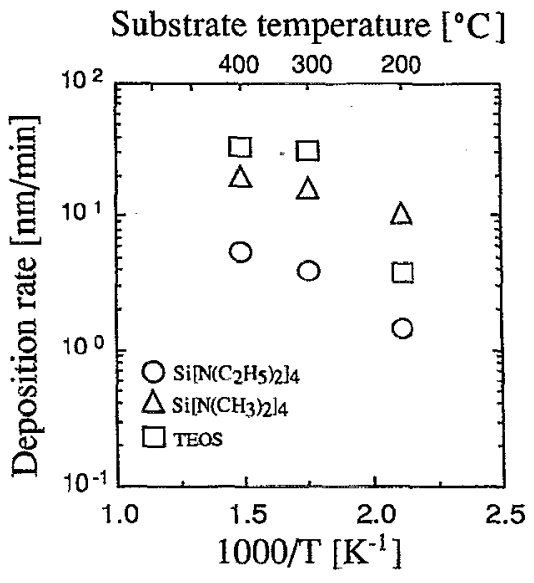

FIG. 2. Arrhenius plots of deposition rates. 

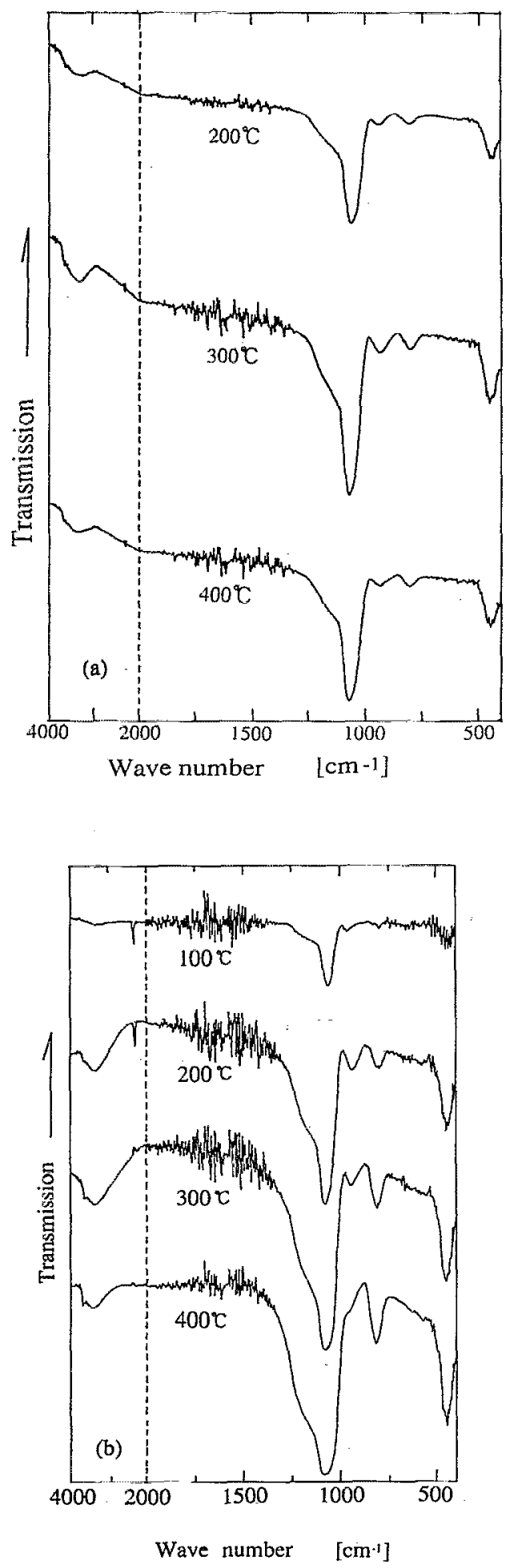

low. When ozone is not contained in oxygen gas, no film was obtained under the experimental condition of this study (at substrate temperatures below $400^{\circ} \mathrm{C}$ ).

Figure 2 shows the Arrhenius plots of deposition rates. Also shown in this figure are the deposition rates of $\mathrm{SiO}_{2}$ films prepared from $\mathrm{Si}\left[\mathrm{N}\left(\mathrm{CH}_{3}\right)_{2}\right]_{4}$-ozone and TEOS-ozone system. ${ }^{5}$ The deposition rate for $\mathrm{Si}\left[\mathrm{N}\left(\mathrm{C}_{2} \mathrm{H}_{5}\right)_{2}\right]_{4}$-ozone system is lower than the latters.

Figures 3(a)-3(c) show infrared absorption spectra of

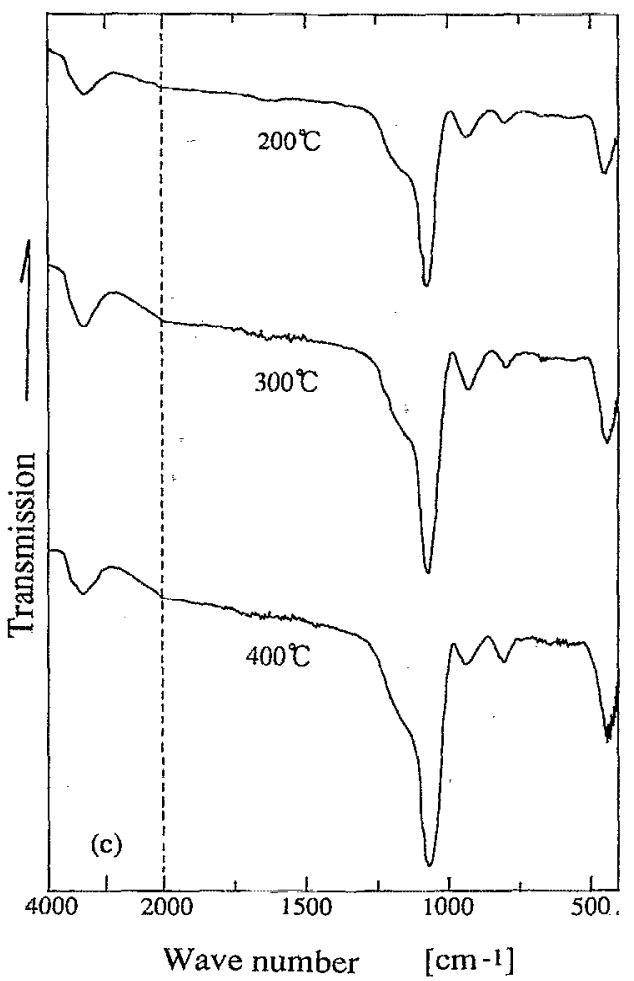

FIG. 3. IR transmission spectra of $\mathrm{SiO}_{2}$ films prepared from (a) $\mathrm{Si}\left[\mathrm{N}\left(\mathrm{C}_{2} \mathrm{H}_{5}\right)_{2}\right]_{4}$-ozone, (b) $\mathrm{Si}\left[\mathrm{N}\left(\mathrm{CH}_{3}\right)_{2}\right]_{4}$-ozone, and (c) TEOS-ozone system.

films deposited at some different substrate temperatures. The spectra are similar to each other; i.e., absorption peaks at about 1080,800 , and $460 \mathrm{~cm}^{-1}$ represent Si-O-Si asymmetric-bond-stretching vibration, network Si-O-Si symmetric-bond-stretching vibration and network $\mathrm{Si}-\mathrm{O}-\mathrm{Si}$ bond-bending vibration. $\mathrm{A}$ trace of the $\mathrm{Si}-\mathrm{OH}$ bond (absorption peak $3300 \mathrm{~cm}^{-1}$ ) can be identified. The peak around $950 \mathrm{~cm}^{-1}$ is due to $\mathrm{Si}-\mathrm{OH}$ bonds containing nonbridging oxygen atoms. Generally nonbridging oxygen gives rise to a 


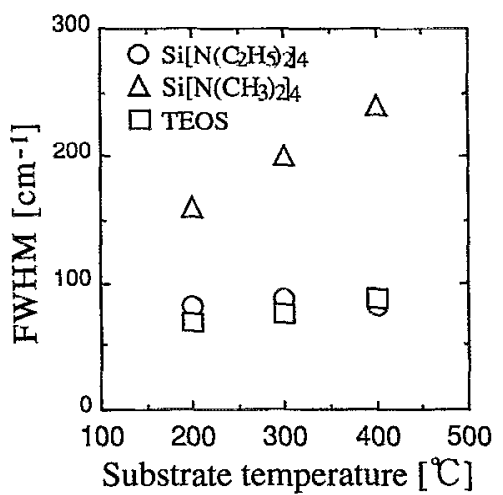

FIG. 4. Full width at half-maximum of the $1080 \mathrm{~cm}^{-1}$ absorption peaks of IR transmission spectra as a function of substrate temperature.

polarized state in the $\mathrm{SiO}_{2}$ film which leads to chemical instability. ${ }^{4}$

Figure 4 shows the full widh at half-maximum (FWHM) of the $1080 \mathrm{~cm}^{-1}$ absorption peaks of infrared transmission spectra as a function of substrate temperature. The value of FWHM is nearly equal to that for TEOS-ozone system, and is much smaller than that for $\mathrm{Si}\left[\mathrm{N}\left(\mathrm{CH}_{3}\right)_{2}\right]_{4}$-ozone system. Thus, the development of the $\mathrm{Si}-\mathrm{O}-\mathrm{Si}$ skeleton in the film prepared from $\mathrm{Si}\left[\mathrm{N}\left(\mathrm{C}_{2} \mathrm{H}_{5}\right)_{2} \mathrm{~J}_{4}\right.$-ozone system is similar to that prepared from TEOS-ozone system.

Figure 5 shows the etch rate of the film dipped into the P-etching solution. With increasing substrate temperature, the etch rate decreases exponentially. It is nearly equal to the

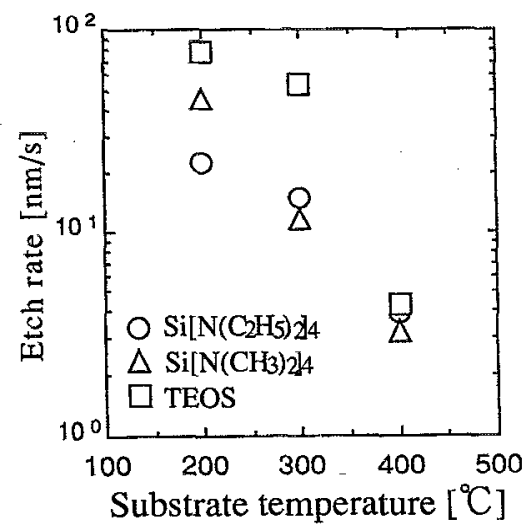

FIG. 5. Etch rate of $\mathrm{SiO}_{2}$ film as a function of substrate temperature.

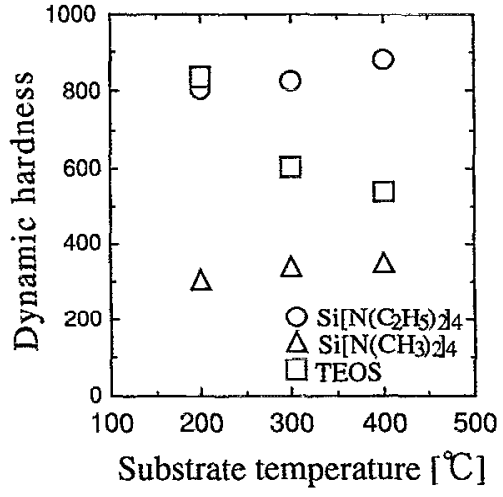

FIG. 6. Dynamic hardness of $\mathrm{SiO}_{2}$ film as a function of substrate temperature.

corresponding value for $\mathrm{Si}\left[\mathrm{N}\left(\mathrm{CH}_{3}\right)_{2}\right]_{4}$-ozone system and smaller than that for TEOS-ozone system. The difference in etch rate is attributable to the difference in content of nonbridging oxygen in the film. As can be seen in FTIR spectra, the peaks around $950 \mathrm{~cm}^{-1}$ for both $\mathrm{Si}\left[\mathrm{N}\left(\mathrm{C}_{2} \mathrm{H}_{5}\right)_{2}\right]_{4}$-ozone and $\mathrm{Si}\left[\mathrm{N}\left(\mathrm{CH}_{3}\right)_{2}\right]_{4}$-ozone systems ${ }^{3}$ are smaller than that for TEOS-ozone system.

Figure 6 shows the dynamic hardness of the film as a function of substrate temperature. It is nearly independent of the substrate temperature, being consistent with the results for $\mathrm{Si}\left[\mathrm{N}\left(\mathrm{CH}_{3}\right)_{2}\right]_{4}$-ozone system. The film is harder than those for $\mathrm{Si}\left[\mathrm{N}\left(\mathrm{CII}_{3}\right)_{2}\right]_{4}$-ozone and TEOS-ozone systems.

In conclusion, silicon dioxide thin films were prepared by a low-temperature atmospheric-pressure chemical vapor deposition method. The raw materials were tetrakis(diethylamino)silane and ozone in oxygen gas. 'The amorphous films were obtained at a substrate temperature above $200^{\circ} \mathrm{C}$. The films were superior in chemical stability and hardness to the films which were prepared from tetraethoxysilane and ozone.

This work was supported by the Ookura Foundation.

\footnotetext{
${ }^{1}$ Y. Ikeda, Y. Numasawa, and M. Sakamoto, NEC Res. Develop. 94, 1 (1989).

${ }^{2}$ K. Kotani, M. Matsuura, A. Fujii, H. Genjou, and S. Nagao, IEDM Tech. Dig., 1989, p. 669.

${ }^{3}$ T. Maruyama and T. Shirai, Appl. Phys. Lett. 63, 611 (1993).

${ }^{4}$ H. Nagayama, H. Honda and H. Kawahara, J. Electrochem. Soc. 135,
} 2013 (1988). 